\title{
MALA CARA: NORMALIDAD Y ALTERIDAD \\ EN LA PERCEPCIÓN Y EN LA REPRESENTACIÓN DEL ROSTRO HUMANO
}

\section{BAD FACE: NORMALITY AND ALTERITY IN THE PERCEPTION AND REPRESENTATION OF THE HUMAN VISAGE}

\author{
Massimo LEONE \\ Universidad de Shanghái / Universidad de Turín \\ massimo.leone@unito.it
}

Resumen: Para discutir de manera razonable de alteridad, primero hay que definir la normalidad. La normalidad de los patrones que determinan la percepción y la representación de rostros humanos tiene que definirse a la vez en relación a la neurofisiología humana de la percepción de rostros, resultado de la evolución biológica de la especie, y a la influencia de una cultura visual sobre ella. La semiótica estructural y, en particular en análisis plástico de las configuraciones visivas, puede ser adoptada como metodología para averiguar lo que una semiosfera cultural considera como núcleo de normalidad en la percepción y especialmente en la representación de rostros. Solamente en relación con este núcleo se puede medir la distancia, a partir de ella, de rostros que una cultura visual considera como otros, anormales, o incluso ilegales.

Palabras clave: Rostro. Percepción. Representación. Normalidad. Alteridad.

\begin{abstract}
So as to reasonably discuss about otherness, one should first define normality. The normality of patterns determining the perception and representation of human visages must be defined in relation to both the human neurophysiology of face perception, resulting from the biological evolution of the species, and the influence of a visual species on it. Structural semiotics, particularly the plastic analysis of visual configurations, can be
\end{abstract}


adopted as methodology so as to ascertain that which a cultural semiosphere considers as its kernel of normality in the perception and especially in the representation of visages. Only in relation to such kernel can the distance from it of visages that a visual culture considers as other, abnormal, or even illegal, be measured.

Key Words: Visage. Perception. Representation. Normality. Alterity.

"Nam ut imago est animi voltus sic indices oculi". Cicerón, Orator

\section{LA TRAMPA DE LA ALTERIDAD}

Lapalabraalteridad constituye un peligro parala reflexiónintelectual ya que a menudo se utiliza no para conducir una investigación teórica determinada sobre los fundamentos ontológicos o las manifestaciones fenomenológicas de la identidad y de sus dialécticas, sino para otorgar al discurso académico una pseudoética de la solidaridad, la cual evoca un imaginario político contemporáneo de tragedias humanas, pero no contribuye en absoluto a su conocimiento, y aún menos a su resolución, sino que las instrumentaliza para construir una retórica académica de la relevancia e incluso de la urgencia. La hipocresía ética de este tipo de discurso académico, muy abundante especialmente en entornos intelectuales mediocres, es simplemente disgustosa, ya que se aprovecha de la miseria humana para edificar una identidad y una distinción. Desde el punto de vista estrictamente teorético, muchas locuciones pseudointelectuales que utilizan palabras como otro o alteridad de esta manera, es decir, como ocasión de turismo académico, no tienen ningún sentido, sobre todo porque no definen de alguna manera la conceptualización de la alteridad.

En el dominio específico de una reflexión sobre el sentido del rostro, por ejemplo, no habría nada más intelectualmente fácil, deshonesto y fundamentalmente vacío que hablar de una semio-ética del rostro de la alteridad, proponiendo una versión pseudo-secularizada de un discurso esencialmente plasmado por la religión cristiana de proximidad emocional y ética hacia lo que es diferente y aún más hacia lo enemigo o lo abyecto. 
No se ve la utilidad de estos desdoblamientos laicos de la moral cristiana, los cuales logran decir menos y peor que lo que consigue expresar un cura de media formación y capacidad retórica. La cantidad de curas seculares que circulan por los congresos académicos es asombrosa.

La especificidad del discurso académico consiste, al revés, en una investigación a la vez teórica y empírica sobre el sentido de la alteridad de un rostro, una investigación que tiene que ser aún más objetiva y racional justamente si desea de alguna manera proponerse como fundamento filosófico de una actitud ética. Cabe entonces reflexionar sobre las condiciones fenomenológicas a partir de las cuales se puede desprender un sentido de la alteridad del rostro ${ }^{1}$.

\section{LOS REQUISITOS ESENCIALES DE LA PERCEPCIÓN DE ROSTROS}

Una cuestión preliminar consiste en interrogarse sobre los requisitos fenomenológicos mínimos para que se pueda manifestar la percepción de un rostro (Calder, 2011). En palabras más sencillas, ¿cuáles son los elementos necesarios, y cuáles los suficientes, para que un rostro aparezca visualmente? Esta pregunta es eminentemente semiótica, pero no puede encontrar una respuesta únicamente en el marco de la semiótica; sería totalmente parcial e inútil descuidar el hecho de que la percepción y el reconocimiento de un rostro por una mirada humana sin patologías neurofisiológicas se conforma con unos patrones fundamentales que no dependen de la cultura más que de las características biológicas de nuestra especie humana (Young, 2016). Estas características pueden ser influenciadas por condicionamientos socioculturales, pero permanecen en la base de toda especificación histórica de un mecanismo que es primariamente biológico (Wilkins, 2017). Postular que la cultura pueda generar unas socio-fisiologías particulares de la percepción corresponde a un pensamiento profundamente ideológico cuyo valor teorético, en relación con la ciencia actual, sería inexistente. Al revés, como demuestran las pruebas experimentales de la psicología cognitiva de la percepción, los

\footnotetext{
${ }^{1}$ Para una lista selecta de publicaciones sobre el sentido del rostro, pueden consultarse las referencias bibliográficas.
} 
seres humanos perciben rostros primariamente porque poseen una facultad neurológica innata para hacerlo.

El papel específico de la semiótica consiste en reflexionar sobre las interacciones entre esta facultad neurofisiológica y cognitiva y el medioambiente sociocultural (Belting, 2013). El estudio semiótico de la pareidolia es imprescindible para comprender cuáles son las configuraciones de estímulos visuales que conducen a la percepción de rostros. La emergencia misma de la pareidolia, o sea, de la percepción de rostros a partir de configuraciones visuales que no contienen caras o representaciones de caras, demuestra el origen neurofisiológico de la cognición visual de rostros (Coates, 2012): cuando estas configuraciones se manifiesten en el medioambiente, es muy difícil para una cognición humana no patológica no identificarlas como un rostro. Otras pruebas empíricas de esta dinámica cognitiva se encuentran en el estudio neurofisiológico del síndrome de Charles Bonnet, a saber, de la tendencia de individuos usualmente geriátricos que han perdido la vista a tener imágenes mentales de rostros monstruosos. Esta experiencia se explica precisamente en relación con la presencia de una actividad cerebral que crea imágenes interiores cuando las exteriores estén ausentes, y de crearlas en conformidad a módulos cerebrales primarios, como el del reconocimiento de rostros, por ejemplo (Groebner, 2015).

\section{LA SEMIÓTICA PLÁSTICA DE LA PERCEPCIÓN FACIAL}

El estudio sistemático de las configuraciones pareidólicas faciales puede sugerir cuáles son las condiciones visivas necesarias y cuáles las suficientes para que se perciba un rostro. Este estudio se puede conducir incluso en el marco de la semiótica estructural de escuela greimasiana, ya que, al final, las dichas condiciones se pueden traducir, en el metalenguaje de esta disciplina, como los elementos que definen el formante plástico de un rostro. Conforme a la metodología clásica de este tipo de análisis, se pueden reconocer por lo tanto una dimensión eidética, una topológica, una cromática, e incluso una textural o matérica del formante plástico del rostro, pero sin olvidar que estas dimensiones se pueden separar por completo solamente a nivel teórico, ya que en la percepción visual la forma, 
la estructura topológica, el color la materia se co-determinan mutuamente de manera muy compleja ${ }^{2}$. También cabe subrayar que el rostro, en todas las culturas visuales humanas, no es una figura simple, sino una figura compuesta de otras figuras según una relación de figura englobante a figuras englobadas: incluso las lenguas lexicalizan no sólo la primera de varias maneras, en castellano con palabras como rostro, cara, facha, semblante, sino también las figuras englobadas, como boca, nariz, ojos, etc. La centralidad visual del rostro en las culturas humanas se manifiesta también en el hecho que su lexicalización a menudo presenta varios niveles de articulación, por ejemplo, en la individuación de la figura rostro, que engloba la figura ojo, que engloba la figura bulbo ocular, que engloba la figura pupila. Esta hiperlexicalización es particularmente evidente en los léxicos especializados, como el de la anatomía, por ejemplo, pero caracteriza también el registro común de muchas lenguas.

No solamente la figura del rostro, por lo tanto, sino también sus subfiguras, poseen sus propios formantes plásticos; un fenómeno que quizás no haya sido suficientemente estudiado por la semiótica visual estructural es que las relaciones entre estos formantes plásticos y las figuras que ellos componen y de la que permiten la lexicalización mudan al mudar las relaciones mereológicas entre figuras y subfiguras, ya que las segundas por un lado poseen su autonomía de figuras reconocidas por una cultura visual, pero por otro lado intervienen como elementos en el formante plástico de las subfiguras que componen. En términos más sencillos: un ojo es una figura que tiene un preciso formante plástico pero que, al mismo tiempo, puede manifestarse visualmente como subfigura en el formante plástico de un rostro.

La dificultad del análisis de esta relación y, más en general del estudio de la semiótica plástica del rostro, consiste en el hecho que los requisitos esenciales para que se perciba un ojo aislado del rostro son diferentes de los requisitos esenciales para que un ojo sea percibido en el marco de un rostro. Si se dibuja un punto negro en una superficie blanca, este punto, en ausencia de otros elementos contextuales, no será suficiente para dar lugar al formante plástico de un ojo. Sin embargo, si se dibuja un

\footnotetext{
${ }^{2}$ En particular, la dimensión de la textura material parece derivada en relación con las otras tres, a menos que no se trate de una percepción no visual sino aptica del rostro (la de los no-videntes, por ejemplo).
} 
círculo alrededor de este punto, y si el punto se encuentra en uno de los dos cuartos superiores del área circular así delimitada, se generará una configuración visual suficiente, aunque no necesariamente determinará la percepción de un rostro y de un ojo dentro de él.

Los dos elementos plásticos, el punto y el círculo, están en una relación de codependencia, ya que el primero sin el segundo no podría expresar suficientemente la idea de un ojo, pero también el segundo sin el primero no podría evocar suficientemente la idea de un rostro. Cuando aparezcan en la misma configuración, al revés, los dos elementos determinan la formación de un formante plástico suficiente para la evocación visual de la figura rostro, de la subfigura ojo, pero inclusive de la sur-figura cabeza, que aparece inevitablemente cuando aparezca la figura rostro. La relación entre subfigura ojo y sur-figura rostro, por un lado, y, por otro, la figura rostro y su sur-figura cabeza son, sin embargo, diferentes, ya que la evocación de la tercera, o sea de la sur-figura cabeza, no depende de la manifestación de una configuración visual, sino de las implicaciones semánticas de una configuración visual; si rostro, entonces cabeza: esta es la regla que, en la enciclopedia visual de muchas culturas humanas, da lugar a tal implicación. Se trata de una implicación conceptual y no perceptual, ya que no es necesario añadir ningún elemento plástico al formante plástico del rostro para que implique ipso facto la idea de una cabeza.

Otras implicaciones son posibles, pero son menos evidentes. Por ejemplo, la evocación de la sur-sur-figura del cuerpo normalmente no surge de manera igualmente espontánea a partir del formante plástico del rostro, ya que, en muchas culturas visuales, la separación visual y semántica entre rostros y cabezas, que sin embargo existe, es netamente inferior a la separación semántica entre rostros y cuerpos. Además, la relación entre figuras y sur-sur-figuras normalmente tiene que pasar por las sur-figuras, o sea se puede evocar un cuerpo a través del formante plástico de una cabeza más fácilmente de cómo se pueda hacerlo a través del formante plástico de un rostro, por ejemplo, añadiendo el formante plástico de la subfigura del cuello o una representación de la tridimensionalidad.

De todas maneras, las relaciones mereológicas y jerárquicas entre figuras y subfiguras se pueden describir en el metalenguaje de la semiótica plástica. Por ejemplo, el formante plástico de un ojo en relación con una cara es un elemento visual eidéticamente puntiforme y topológicamente 
englobado por un elemento visual eidéticamente circular y situado en la parte superior del mismo, en posición asimétrica. El color no parece fundamental en la constitución de este formante plástico, aunque pueda intervenir para acentuar su perceptibilidad o incluso para complementar el efecto plástico de los elementos eidéticos o topológicos, cuando estos sean insuficientes. En el marco de una interpretación dinámica y, por lo tanto, tensiva de los formantes plásticos, se puede ejercer una prueba de conmutación visual para averiguar lo que acontece al formante plástico mismo cuando sus elementos esenciales son progresivamente alterados. Por ejemplo, si el punto dentro del círculo se desplaza progresivamente desde una posición asimétrica a una posición simétrica, o desde la semiesfera superior a la inferior, resultará progresivamente más difícil reconocer un rostro.
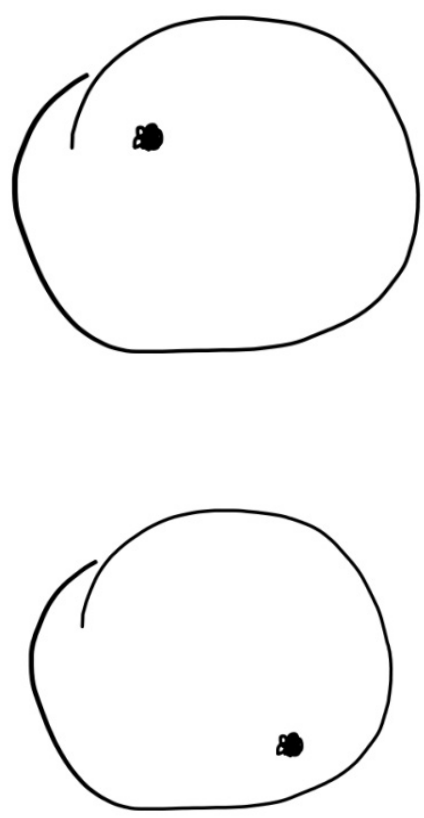

Figura 1. La primera configuración visual puede aparecer como rostro mucho más fácilmente que la segunda, ya que respeta una regla fundamental de la gramática visual de los rostros humanos: los ojos se sitúan en la parte superior del círculo del rostro. 

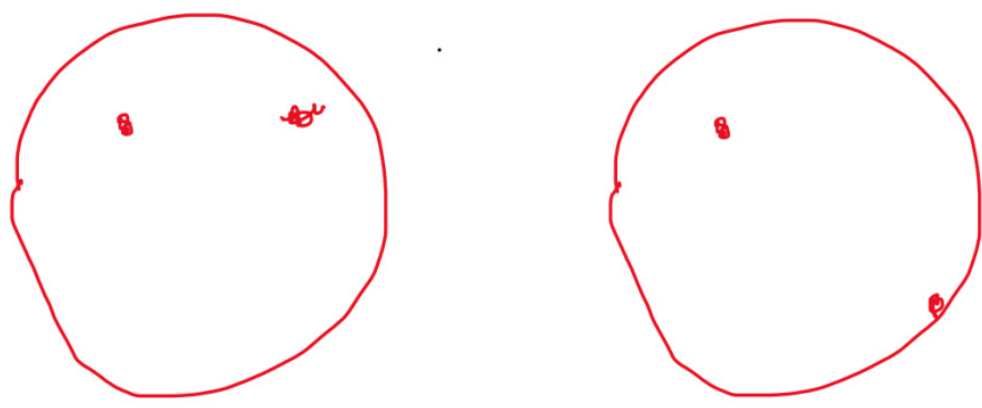

Figura 2. La primera configuración visual puede aparecer como rostro mucho más fácilmente que la segunda, ya que respeta otra regla fundamental de la gramática visual de los rostros humanos: los ojos se sitúan ambos en la parte superior del círculo del rostro, en posición simétrica en relación con el centro, dentro de una distancia variable pero determinada.

\section{SEMIÓTICA EXPERIMENTAL DE LA PERCEPCIÓN FACIAL}

En la elaboración de experimentos cognitivos que intenten averiguar inductivamente estas condiciones de perceptibilidad, no habrá que olvidar, como se hace a menudo de manera sorprendente, los psicólogos de la Gestalt, que el funcionamiento de la cognición visual en la construcción de una figura no es lo mismo que su funcionamiento en la deconstrucción de la misma figura. Por ejemplo, si tras haber averiguado que un punto y un círculo con las características plásticas que se han descrito son suficientes para evocar la idea de un rostro en un sujeto perceptor, se borra el círculo y se expone el mismo sujeto a la misma imagen, el sujeto seguirá reconociendo el punto (que es el único elemento visual que permanece) como un ojo, ya que la memoria del círculo preexistente será suficiente para caracterizar el punto como ojo.

Esto explica también la razón por la cual imágenes pareidólicas puras de rostros sean raras, o sea, son raras las configuraciones visuales que necesariamente y en todos los sujetos perceptores evocan necesariamente 
unos rostros. Sin embargo, cuando una imagen pareidólica sea reconocida como rostro, por ejemplo, gracias a la presión de algunos elementos contextuales, será imposible volver atrás, hacia una no-percepción del rostro en la configuración pareidólica.

\section{HACIA UNA SEMIÓTICA DE LAS CULTURAS VI- SUALES DEL ROSTRO}

Corresponde a la semiótica estudiar los condicionamientos contextuales que moldean el nivel básico de recepción de las imágenes faciales (Guido et al., 2017). En toda la especie humana, en efecto, en un rostro no patológico los ojos se sitúan en la parte superior del rostro, son dos, y son en posición simétrica en relación con el centro. Sin embargo, las culturas visuales pueden variar considerablemente la manera en la que suelen presentar y representar rostros (Magli, 2016).

Desde la perspectiva de la semiótica plástica, por ejemplo, la cuestión del rostro femenino que en el fundamentalismo islámico y especialmente en el área geográfica y cultural de Afganistán se oculta casi por completo detrás de varias series de rejas de tejido, o sea, detrás del burqa, no concierne únicamente la recepción occidental de esta ideología religiosa, sino también la recepción visual de la semiótica plástica que esta ideología conlleva. En la cultura visual contemporánea de Occidente, en la imposibilidad de ver la totalidad del rostro, lo que se percibe no es un rostro sino una cabeza, o sea una cabeza sin su subfigura, el rostro, y sin su sub-sub-figura, los ojos. Otras formas de ocultamiento de la cara femenina en el fundamentalismo islámico, como el niqab, que oculta la cara, pero deja ver los ojos, seguramente no son más aceptables desde el punto de vista ideológico, pero lo parecen porque son más aceptables desde el punto de vista de la cultura visual del rostro en Occidente (Leone, Riedmatten, y Stoichita, 2016). 

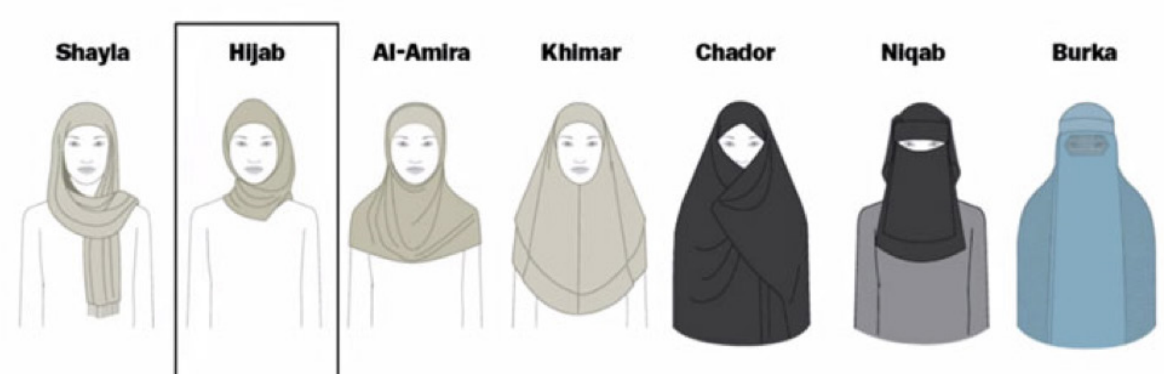

Figura 3. Presencia visual y plástica del rostro en relación con varios tipos de velo islámico.

Este ejemplo confirma que, para identificar las configuraciones perceptuales de presentación y de representación del rostro que, en la cultura visual occidental, evocarían una idea de alteridad, con todos los matices posibles desde la variación sutil y hasta divertida y apreciada hasta la monstruosidad aterrorizadora, habría primero que definir la estructura plástica que la neurofisiología humana asocia a la percepción de rostros, y luego estudiar las presiones contextuales que otros sistemas semióticos, otras imágenes y, sobre todo, una cultura visual específica ejercen sobre estos patrones neurofisiológicos, influenciándolos de manera muy profunda (Guédron, 2015). Solamente describiendo el nivel básico de la presentación y representación facial o, por lo menos, su núcleo tensivo central, se podrán enseguida medir los efectos de distanciación progresiva a partir de este sentido perceptivo y visual común, de la variación hasta la monstruosidad (Leone, 2016).

\section{CASO DE ESTUDIO: NÚMERO DE OJOS Y ALTERIDAD}

Por ejemplo, en relación con la relación plástica entre los ojos y el rostro, la presentación o representación con un número de ojos inferior o superior a dos, que es el estándar de la especie humana, produce diferentes efectos de alteridad. Por un lado, rostros con muchos ojos abundan en los mitos antiguos, así como en las representaciones fantásticas de toda época, incluida la de la ciencia ficción contemporánea. Seres con tres o más ojos son caracterizados en el sentido de un potenciamiento de la mirada y de sus 
connotaciones culturales, pero sobre todo se presentan como rostros otros, cuya configuración visual plástica, antes de toda connotación cultural, ya contradice la normalidad y evoca lo monstruoso. En la figura que sigue, se reproduce un fresco de Pinturicchio y escuela que representa el mito de Hermes encantando con su música a Argo, el ser mitológico con ojos en todo el cuerpo, cuya monstruosidad sin embargo es limitada por ser la cara de Argo.

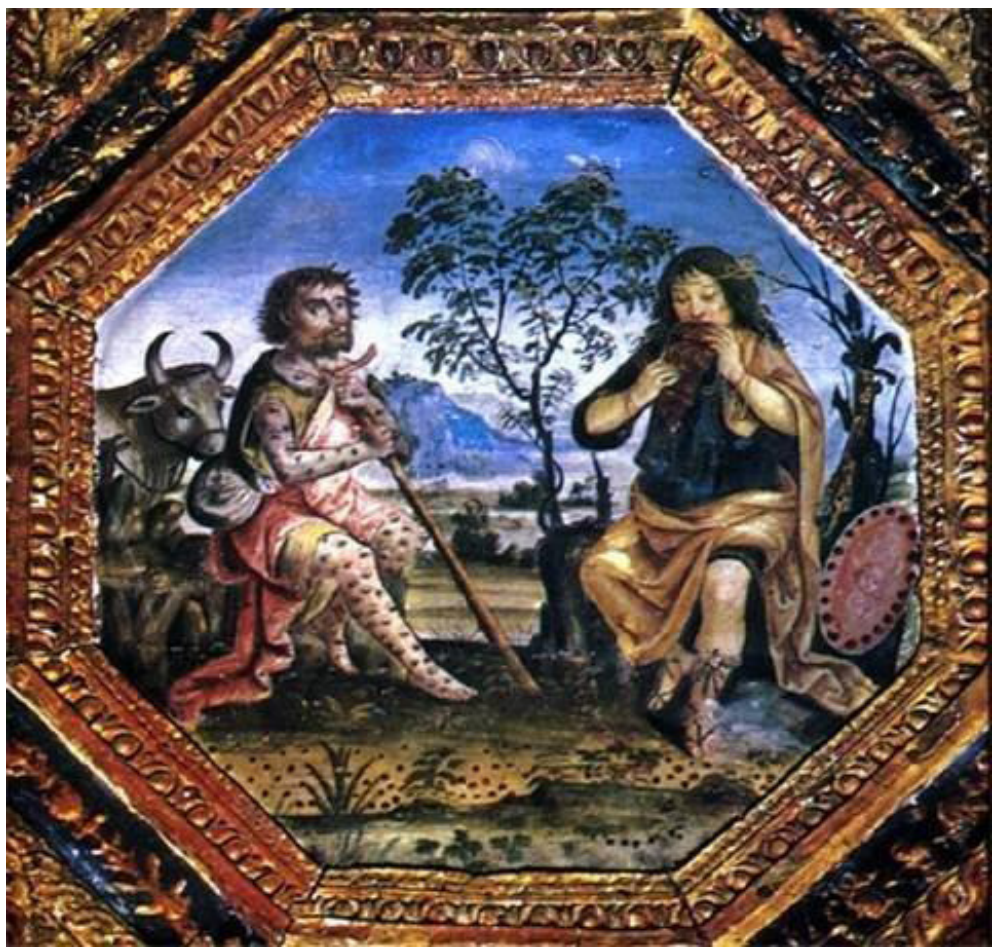

Figura 4. Pinturicchio y escuela. 1493. Hermes encanta a Argo (Octágono 3). Fresco. Roma, Palacios Vaticanos, Appartamento Borgia, Sala dei Santi.

Lo monstruoso también se puede evocar reduciendo el número de ojos, con efectos distintos en el caso de rostros monóculos, como el de Polifemo, y ojos aislados, como el que aparece en el triángulo con un ojo al interior utilizado como referencia simbólica a dios en la cultura visual cristiana o en la masónica. 


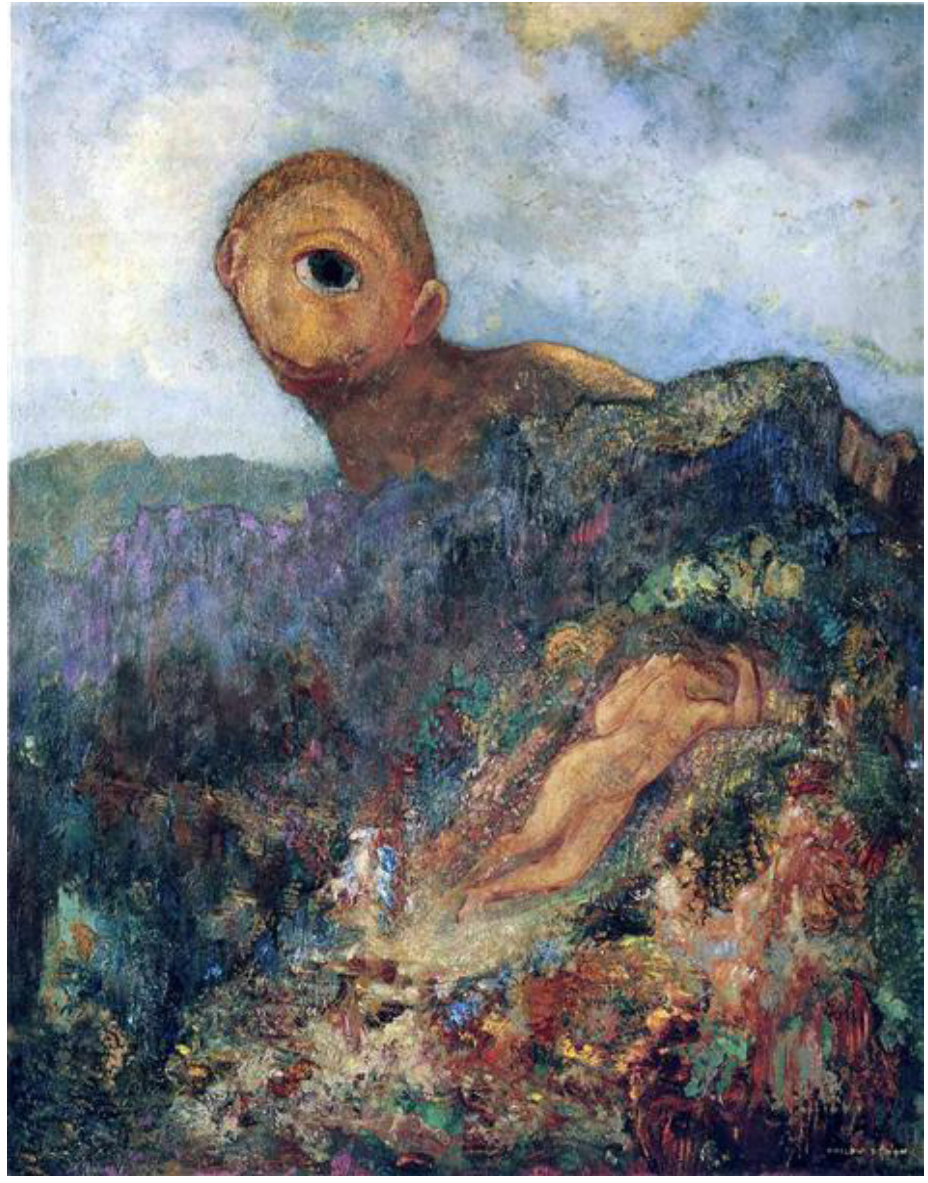

Figura 5. Odilon Redon. 1915. El cíclope. Óleo sobre lienzo. 51 x 64 cm. 


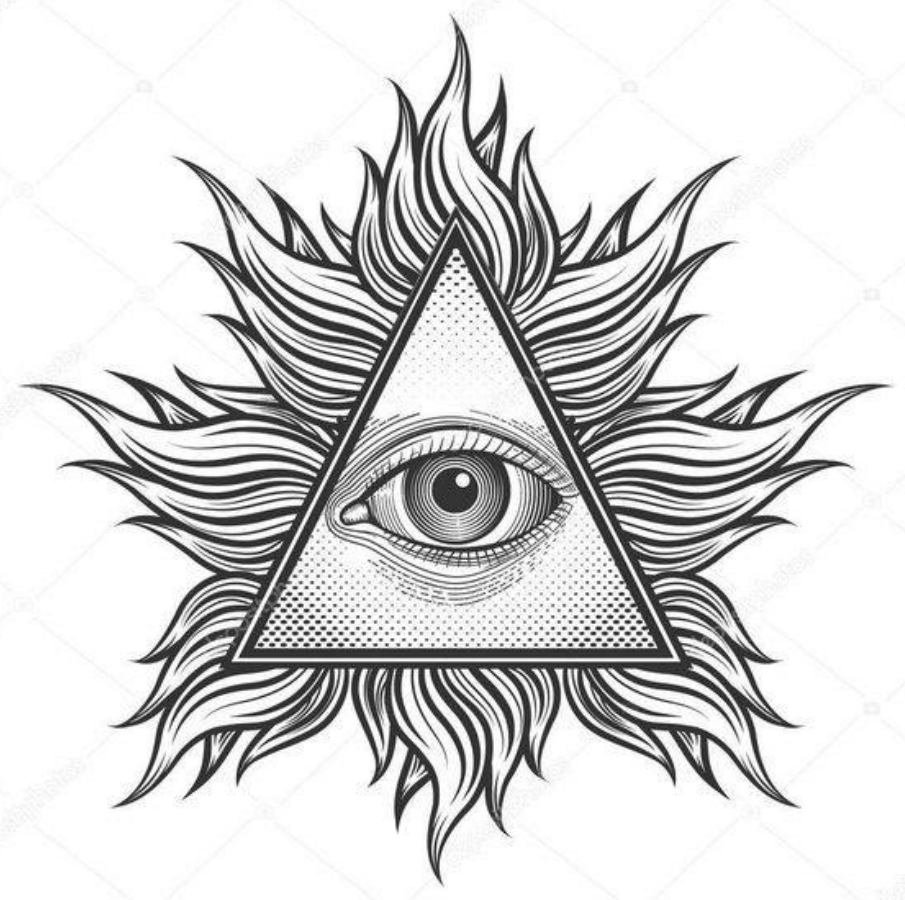

Figura 6. Anónimo: El ojo de la providencia.

En este último caso, sin embargo, el potenciamiento de la connotación simbólica del "ojo de la providencia" se debe no solamente al hecho de que sea uno, sino también al hecho de que aparezca dentro de una figura englobante, el triángulo, cuya estructura eidética difícilmente puede evocar un rostro. En el triángulo con un ojo en medio los fieles ven el ojo de Dios y su mirada, pero no ven su rostro. Existen por lo tanto representaciones de alteridad facial que pasan por la representación de un ojo sin rostro, de dos ojos sin rostro, como en la imaginación surrealista de Dalí, pero también existen otras representaciones que, al revés, proponen rostros sin ojos, como en los maniquís representados en la pintura metafísica de Giorgio De Chirico: en este caso, se perciben no sólo cabezas sin rostros, sino cabezas en las que los elementos plásticos del rostro han sido modificados y transformados en unas líneas discontinuas las cuales evocan un rostro pero de forma alterada, y no en el sentido de un potenciamiento monstruoso de la mirada, como acontece en los personajes mitológicos de múltiples ojos, sino en el sentido de una proyección de la mirada hacia un 
mundo no perceptual, el mundo de la introspección y de la metafísica.

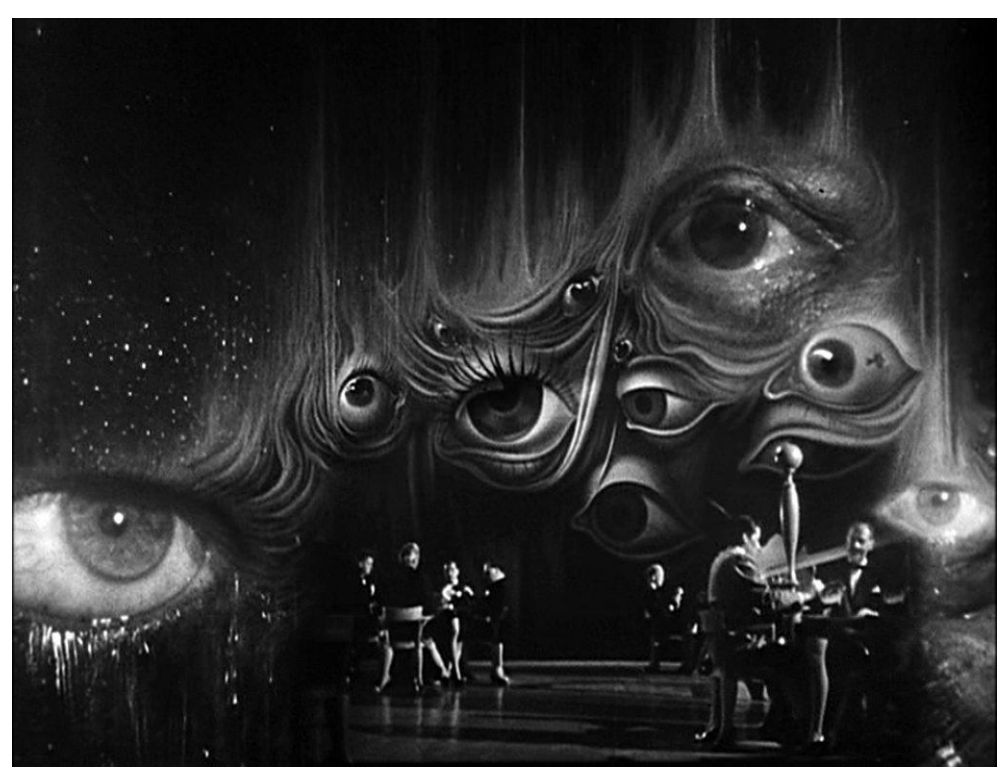

Figura 7. Salvador Dalí. Ojos para la escenografía de la película Spellbound (1945), de Alfred Hitchcock. 


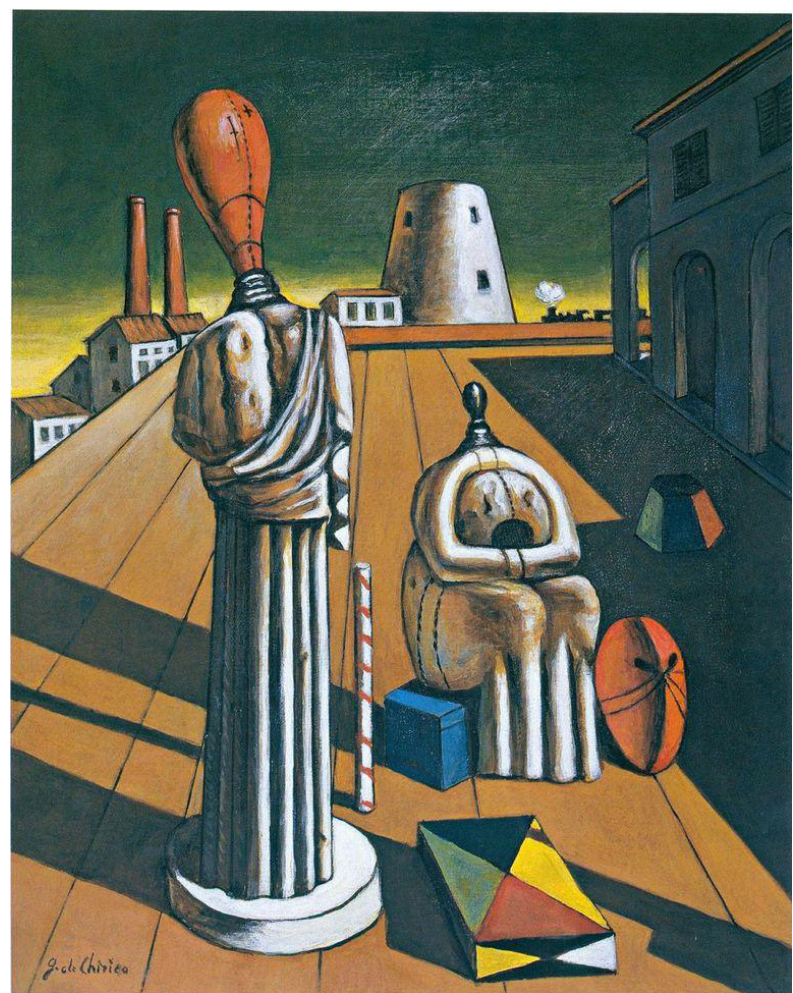

Figura 8. Giorgio de Chirico. 1916-1918. Le muse inquietanti. Óleo sobre lienzo.

$97 \mathrm{~cm}$ x 66 cm. Milán. Colección Gianni Mattioli.

En otros casos, una alteridad menos monstruosa, pero a veces igualmente inquietante, se puede construir alterando no el número de los ojos sino su posición en relación con la cara, por ejemplo, en la cara del dibujo animado de Quasimodo en la versión Disney de Nôtre-Dame-deParis, con los ojos que se sitúan casi en el semicírculo inferior de la cara, o modificando la simetría de la forma, del color, y de la posición de los ojos. 


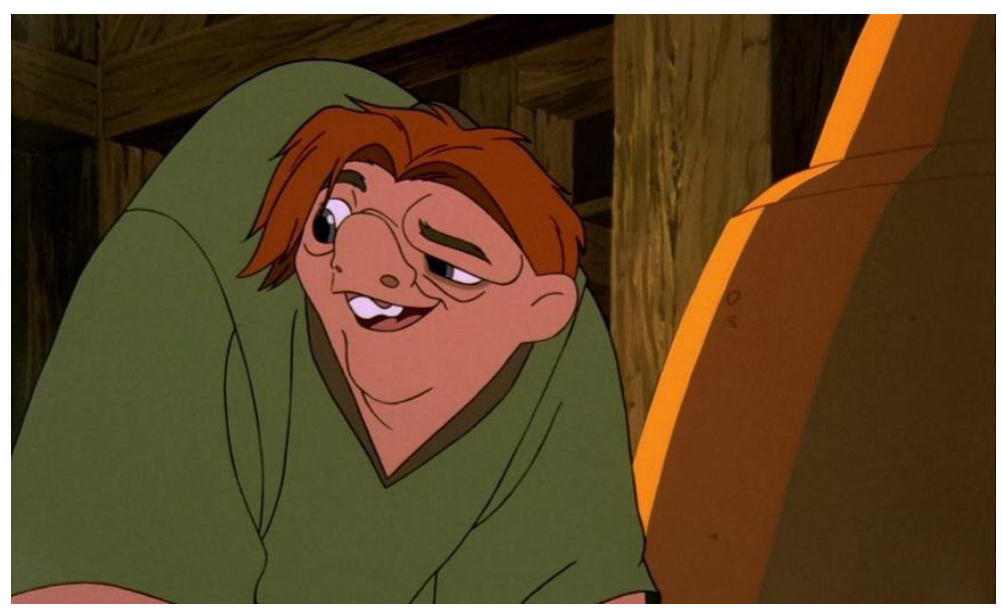

Figura 9. La cara de Quasimodo, de Disney.

Algunas de estas alteraciones pueden ser toleradas por la cultura visual e incluso recibir una connotación positiva de originalidad y de exclusividad social. En este caso también habría que hacer hincapié en las variaciones plásticas de la exclusividad: la asimetría cromática puede fascinar, como en los famosos ojos de dos colores de David Bowie (un caso de anisocoria), e incluso puede fascinar una ligera alteración de la simetría de las pupilas en los ojos, como en el estrabismo de Venus y, sin embargo, una alteración de la simetría vertical de los ojos en relación a la cara, con un ojo más alto que el otro, sería mucho más perturbadora, o evocaría una representación de vanguardia como la del cubismo, el cual justamente construye su poética alterando sistemáticamente la gramática plástica del cuerpo y sobre todo del rostro. 
MALA CARA: NORMALIDAD Y ALTERIDAD EN LA PERCEPCIÓN Y EN LA REPRESENTACIÓN DEL ROSTRO HUMANO

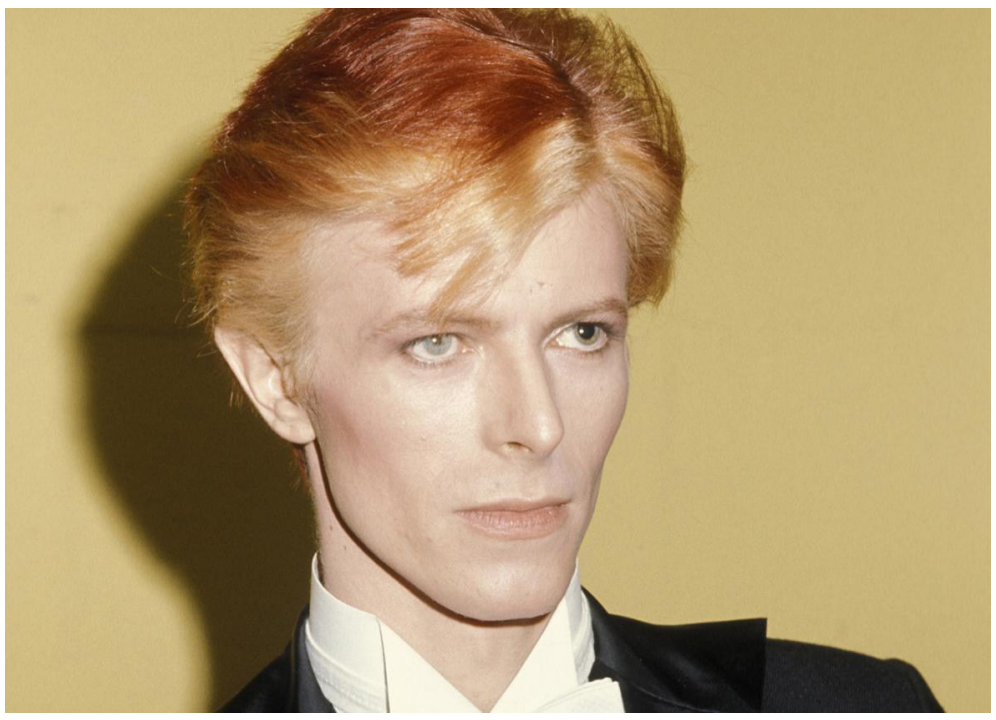

Figura 10: Los ojos de David Bowie.

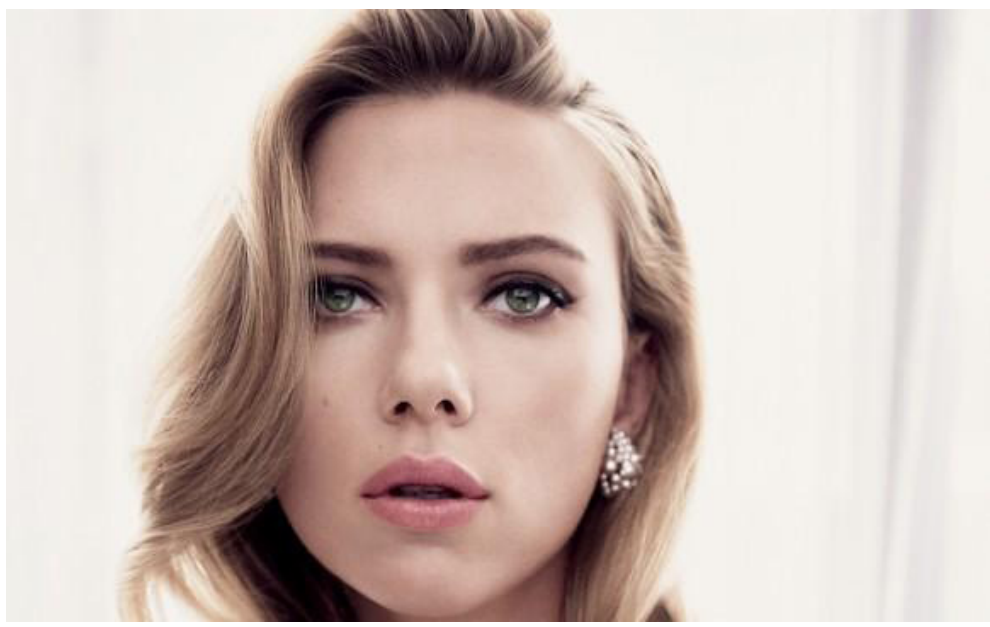

Figura 11. El estrabismo de Venus de Scarlett Johansson. 


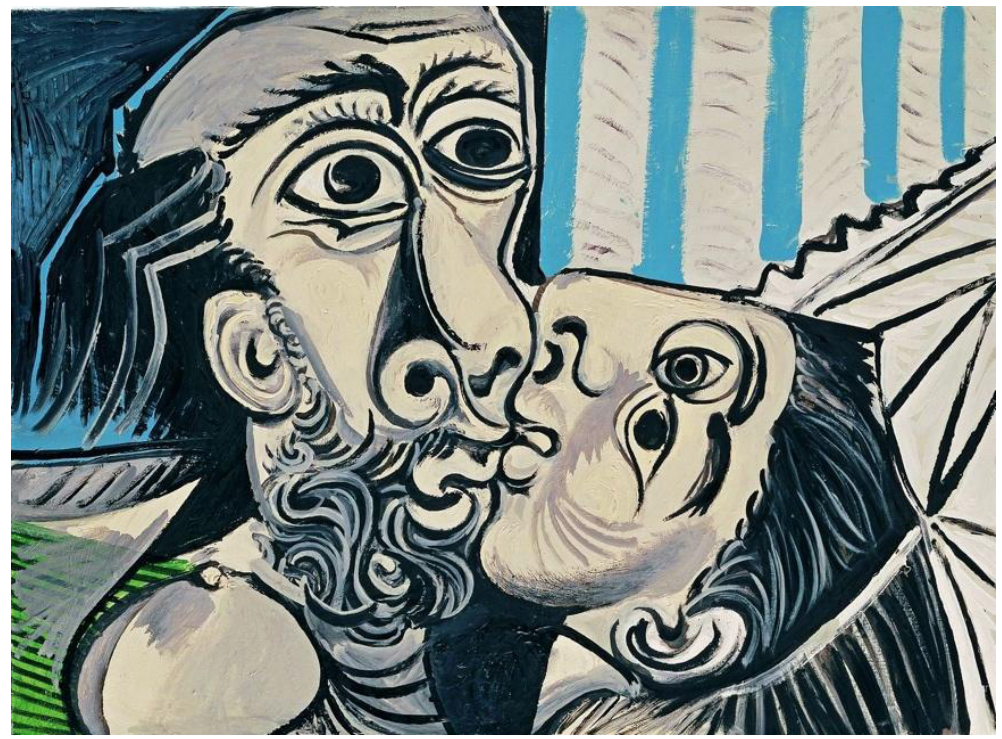

Figura 12. Pablo Picasso. 1969. El beso (Le baiser). Óleo sobre lienzo. París: Museo Picasso.

\section{ROSTROS NORMALES, ROSTROS MONSTRUOSOS}

El tema de la alteración cromática en la percepción del rostro es particularmente sensible, ya que, como Umberto Eco lo subrayaba ya en sus comentarios sobre el racismo, existe una especie de racismo automático, espontáneo, que no está necesariamente relacionado a una ideología, sino a la presión de un sentido común visual el cual, en un determinado grupo étnico, determina el rostro ideal o por lo menos una gama de variaciones aceptables. Aunque no lo queramos, la percepción del rostro en grupos étnicos muy uniformes se construye alrededor de una experiencia de caras humanas donde la variabilidad somática y entonces de pigmentación, o sea, la base fisiológica de la dimensión cromática del rostro humano es muy limitada. Para el individuo que haya vivido toda su vida rodeado por rostros caucásicos muy poco pigmentados y con ojos azules, la aparición de un rostro africano muy pigmentado será percibida necesariamente como una alteridad; esto, sin embargo, y en eso me permito diferenciarme del comentario de Eco, no conlleva necesariamente una discriminación racista; el racista no es quien perciba otro rostro humano como portador de una alteridad perceptual, sino quien asocie a esta alteridad perceptual 
una alteridad antropológica. Es verdad, sin embargo, que en una sociedad en la que ni siquiera se perciba la alteridad perceptual de un rostro de otra etnia, como en las sociedades multiétnicas en las que desde niños se hace experiencia de la diversidad somática humana, es más difícil que se desarrolle una ideología racista.

Establecer los patrones neurofisiológicos de percepción de rostros y sus inflexiones contextuales debería permitir cartografiar una semiosfera del rostro (Leone, 2019b), un diagrama topológico dinámico al centro del cual se sitúe una gama de rostros biológicos y representados cuya configuración plástica quepa dentro de una gama de aceptabilidad estética e incluso normativa, como lo sugerían de manera aún impresionista Deleuze et Guattari en Mille plateaux [Mil mesetas] (1980). La identificación de esta base perceptual es fundamental no en sí misma, sino para medir las dinámicas de distanciación y acercamiento en relación con este núcleo. Por un lado, por ejemplo, subsistirán prácticas de normalización de los rostros, de manera que su presentación biológica o su representación visual se acerquen a este núcleo normativo de definición: actividades como el maquillaje, la cirugía estética, la postproducción de fotos digitales, etc. sólo toman plenamente sentido en relación a esta dinámica (Boehm, 2015). Por otro lado, es igualmente en comparación a este núcleo normativo que se podrá describir lo que acontece en la periferia de la semiosfera, donde aparecen los rostros de la alteridad eidética, topológica, cromática e incluso se manifiestan trágicos ejemplos de exclusión social.

Hoy, por ejemplo, en muchas culturas los animales no humanos no caben dentro de esta semiosfera, como ya lo había intuido filosóficamente Derrida en su comentario sobre Lévinas (1961) (L'animal que je suis), ya que la parte frontal de la cabeza de los animales no es identificada visualmente y culturalmente como rostro sino como hocico; pero, más allá de los confines semiesféricos, se encuentran también rostros que no se aceptan porque son excesivamente deformados por la patología y, por eso, condenan los individuos a la exclusión social (Talley, 2014); e incluso se encuentran representaciones de rostros consideradas como inaceptables, los rostros envejecidos excluidos de la representación publicitaria de la belleza, por ejemplo, o los rostros cuya ambigüedad de género es rechazada por la cultura del rostro dominante, con su obsesión por diferenciar los rostros masculinos y femeninos (Boehm y Enno, 1995).

La frontera más reciente de esta tarea de investigación semiótica 
consistirá, en fin, en la necesidad de analizar los procesos culturales y productivos, a veces subrepticios, a través de los cuales los estereotipos visuales, culturales, e incluso étnicos de presentación y representación de los rostros se transmiten a veces de manera subconsciente a las máquinas y a los algoritmos (Leone, 2017), donde desaparecen detrás de una retórica de la neutralidad tecnológica (Edkins, 2015). De este punto de vista, el sentido excluyente de la alteridad es aún más pernicioso en la producción y circulación digital de imágenes de rostro, y necesita una investigación semiótica atenta y puntual (Leone, 2019a).

\section{REFERENCIAS BIBLIOGRÁFICAS}

BELTING, H. (2013). Faces: eine Geschichte des Gesichts. Munich: C.H. Beck.

BOEHM, G. y ENNO, R. (eds.) (1995). Individuum: Probleme der individualität in Kunst, Philosophie und Wissenschaft. Stuttgart: Klett-Cotta.

BOEHM, G. et alii (eds.) (2015). Gesicht und Identität / Face and Identity. Paderborn: Wilhelm Fink Verlag.

CALDER, A. J. et alii (eds.) (2011). The Oxford Handbook of Face Perception. Oxford / New York: Oxford University Press.

COATES, P. (2012). Screening the Face. New York: Palgrave Macmillan. DELEUZE, G. y GUATTARI, F. (1980). Mille Plateaux. Paris: Éditions de Minuit.

EDKINS, J. (2015). Face Politics. New York: Routledge.

GROEBNER, V. (2015). Ich-Plakate: eine Geschichte des Gesichts als Aufmerksamkeits maschine. Frankfurt am Main: S. Fischer.

GUIDO, L. et alii (eds.) (2017). Visages. Histoires, représentations, créations. Lausanne: Éditions BHMS.

GUÉDRON, M. (2015). Visage(s): Sens et représentations en Occident. Paris: Hazan.

LEONE, M.; RIEDMATTEN, H. de e STOICHITA, V. I. (eds.) (2016). Il sistema del velo / Système du voile: Trasparenze e opacità nell'arte moderna e contemporanea / Transparence et opacité dans l'art moderne et contemporain. Roma: Aracne.

LEONE, M. (2016). "Nature and Culture in Visual Communication: 
Japanese Variations on Ludus Naturae". Semiotica. Journal of the International Association for Semiotic Studies 213, 213-245. (2017). "Socio-sémiotique des 'livres à visages". Nouveaux Actes Sémiotiques [Monográfico sobre Sémiotique et engagement, É. Landowski (ed.)] 120, 1-9. Disponible en línea: http://epublications. unilim.fr/revues/as/5816 [24/03/2020].

(2019a). "Précis de sémiotique du visage numérique", En Sémiotique de la littérature, de l'art et de la culture, M. AthariNikazm (ed.), 129-148. Teherán: Universidad Shahid Beheshti.

(2019b). "The Semiotics of the Face in Digital Dating: A Research Direction". Digital Age in Semiotics and Communication [Monográfico sobre Digital Sex and Dating] 2, 18-40.

LÉVINAS, E. (1961). Totalité et infini ; essai sur l'extériorité. La Haya: M. Nijhoff.

MAGLI, P. (2016). Il volto raccontato: ritratto e autoritratto in letteratura. Milano: Raffaello Cortina editore.

TALLEY, H. L. (2014). Saving Face: Disfigurement and the Politics of Appearance. New York: New York University Press.

YOUNG, A. W. (2016). Facial Expression Recognition: The Selected Works of Andy Young. London / New York: Routledge.

WILKINS, A. S. (2017). Making Faces: The Evolutionary Origins of the Human Face. Cambridge, MA: The Belknap Press of Harvard University Press.

Recibido el 2 de marzo de 2020.

Aceptado el 15 de abril de 2020. 